\title{
ACCURACY OF HOLES CREATED BY 3D PRINTING (DMLS)
}

\author{
Daňa Milan, Zetková Ivana, Hanzl Pavel, Hronek Ondřej
}
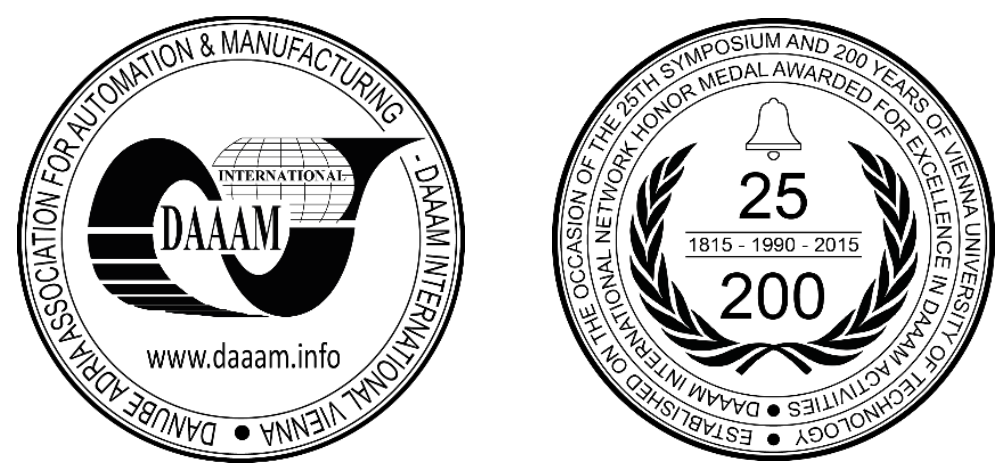

This Publication has to be referred as: Dana, M[ilan]; Zetkova, I[vana]; Hanzl, P[avel] \& Hronek, O[ndrej] (2017). Accuracy of Holes Created by 3D Printing (DMLS), Proceedings of the 28th DAAAM International Symposium, pp.0467-0473, B. Katalinic (Ed.), Published by DAAAM International, ISBN 978-3-902734-11-2, ISSN 1726-9679, Vienna, Austria

DOI: $10.2507 / 28$ th.daaam.proceedings.065

\begin{abstract}
Additive manufacturing ( $\mathrm{AM}$ ) is a very important topic nowadays, therefore this paper is focused on 3D printing of metal. AM for metal covers many methods that are divided into two basic principles: powder bed technologies and powder deposition technologies. This paper is limited to Direct Metal Laser Sintering (DMLS) that works on the principle of a powder bed. This method is based on sintering metal powder in thin layers, layer by layer. It is able to print different kinds of metal, for example stainless steel, maraging steel, Inconel, aluminium, titanium, etc. An EOS M290 machine with maraging steel MS1 powder was used for the experimental part of this article. Almost every mechanical component contains at least one or several holes, therefore it is important to describe how accurately 3D printing can create these holes. The effects of different holes positions on accuracy and geometry are compared. The influence of the size of the hole on the geometry change at the bottom of an arc is investigated. The goal of the experiment is to find the size of a hole which can be printed without support structures and which does not show signs of degradation of its geometry.
\end{abstract}

Keywords: 3D print; Additive manufacturing; DMLS; maraging steel MS1; Holes

\section{Introduction}

Additive manufacturing (AM) is a very extensive area with many methods and several basic principles. One of the most effective AM techniques especially for metal is Direct Metal Laser Sintering (DMLS). This principle is based on the application of a thin layer of powder which is subsequently sintered using a laser beam with a diameter of approximately $80 \mu \mathrm{m}$. The parts are built layer-by-layer. The printed parts are produced from very fine metal powder with spherical grain shape. This technology is suitable for producing components with very complex shapes and for parts that are impossible to produce by conventional technologies. For example, mould parts with conformal cooling, parts with internal cavities, etc.

Many studies have been carried out on Direct Metal Laser Sintering, but most of them are focused on changing the process parameters. This paper is focused on another of area of research in 3D metal printing. This area deals with the geometric limits on this technology from the point of view of internal holes. [10]

Reference [12] is focused on 3D printing, and especially on the geometrical limits of this method. The author has conducted several experiments regarding the printing of thin walls, overhangs and holes and states: 'The holes up to diameter $7 \mathrm{~mm}$ can be printed without support structures while maintaining relatively good geometry and good accuracy. 
These holes are built safely but will have an average of $0.5 \mathrm{~mm}$ of sag at the top of the hole, which is uncontrollable even with supports, and prevents the overall hole from being perfectly circular.' [12] Reference [7] gives a comprehensive set of information about 3D printing rules. The author claims that holes up to a diameter of 10mm can be printed without support structures. Reference [6] is also focuses on 3D metal printing and especially on printing several basic features such as thin walls, narrow gaps and especially holes. The author measures the accuracy of holes using a microscope. The range of holes was chosen from $0.1 \mathrm{~mm}$ to $6 \mathrm{~mm}$. Holes smaller than $0.45 \mathrm{~mm}$ were not printed. From the results, it can be stated that the printed holes are smaller than the model.

Holes with a horizontal axis are printed without problems and with very good geometry. The holes in this position can be printed without limitations to their size. However, printing holes with vertical axes has several limitations. The vast majority of publications deal with the geometry of printed holes, especially the poor vaulting of holes. This claim will be experimentally verified. The geometry of holes is not good either at the bottom of hole. This problem will be described further in this article.

\section{Material and experimental devices}

\subsection{Material MSI}

The material used for additive manufacturing is maraging steel with the commercial marking MS1. The conventional European standard designation is 1.2709 and, according to DIN, is X3NiCoMoTi 18-9-5. The material composition is shown in Table 1. [1],[2],[3],[4]

\begin{tabular}{|c|c|c|c|c|c|c|c|c|c|c|}
\hline Elements & $\mathbf{F e}$ & $\mathbf{N i}$ & $\mathbf{C o}$ & $\mathbf{M o}$ & $\mathbf{T i}$ & $\mathbf{A l}$ & $\mathbf{C r}, \mathbf{C u}$ & $\mathbf{M n}, \mathbf{S i}$ & $\mathbf{C}$ & $\mathbf{S}, \mathbf{P}$ \\
\hline in $\%$ & balance & $17-19$ & $8.5-9.5$ & $4.5-5.2$ & $0.6-0.8$ & $0.05-0.15$ & $\leq 0.5$ & $\leq 0.1$ & $\leq 0.03$ & $\leq 0.01$ \\
\hline
\end{tabular}

Table 1. Material composition [2]

This kind of steel is characterized by having very good mechanical properties and is suitable for welding, machining, polishing and coating. It is easily heat-treatable. The steel is supplied in powder form. The powder particles have different diameters, which leads to a better volume fraction of the metal. The diameters of particles range from 10 to 40 micrometres. [2],[3],[4]

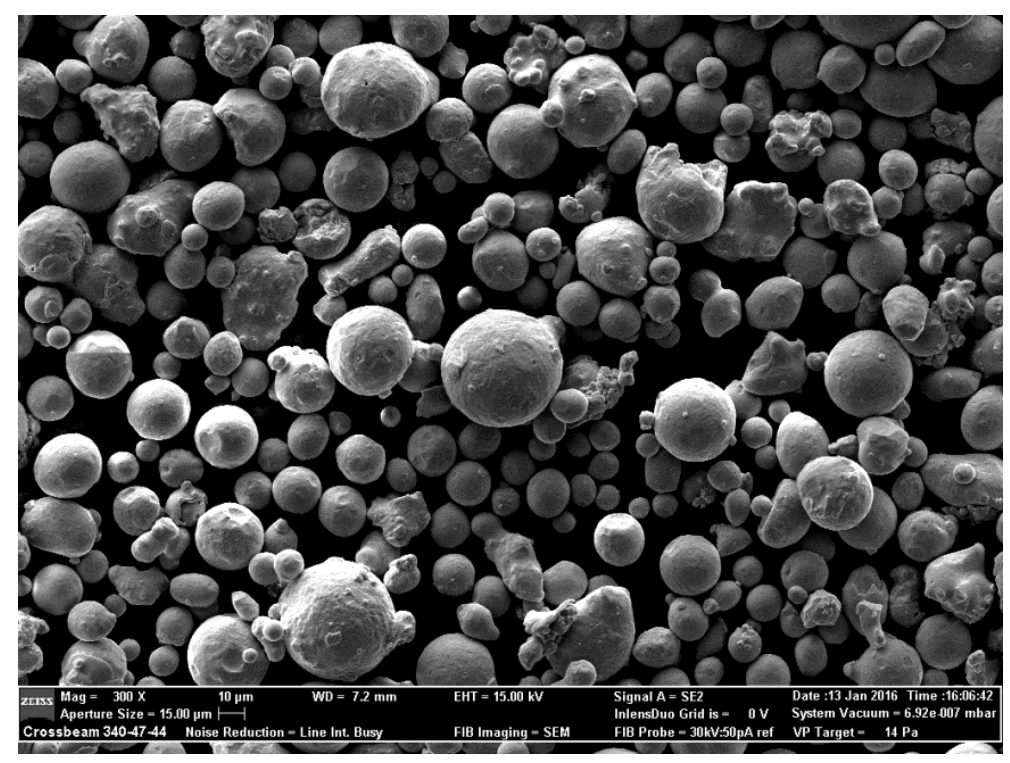

Fig. 1. The powder particles

\subsection{Experimental devices}

The EOS M290 was used for printing the experimental samples with holes. This printer is a very sophisticated device that enables fast, flexible and cost-effective production from various metals, for example titanium, aluminium, stainless steel, maraging steel, etc. The building volume is $250 \times 250 \times 325 \mathrm{~mm}$. A 400-watt fibre laser provides an exceptionally high beam quality combined with stable performance. The scanning speed can be up to $7 \mathrm{~m} / \mathrm{s}$. The experimental print started with the process parameters as recommended by the manufacturer. Individual parameters such as laser power, scan speed and so on are included under these designations. For example, the parameters for printing the part are: laser 
power $285 \mathrm{~W}$, Laser speed $960 \mathrm{~mm} / \mathrm{s}$, Hatch $0.11 \mathrm{~mm}$, etc. The skin of the part has different parameters to the core of the part. The layer thickness was 40 micrometres. [2],[8]

An IFM G4 optical-scanning microscope from Alicona was used to measure the samples. This device allows scanning of the holes and high resolution measurements. The main advantage of this microscope is its high scanning speed and simplicity of measuring. [11]

\subsection{Experimental setting}

The samples were printed using support structures. The height of the support structures was 5mm to allow removal of the samples from the building platform using a bandsaw. The structure types 'Volume' and 'Block' were used together. The support structure of the block was set as follows: Hatching 0.65 x $0.65 \mathrm{~mm}$, Hatching teeth - Height $1.0 \mathrm{~mm}$, Top length $0.35 \mathrm{~mm}$, Base length $0.8 \mathrm{~mm}$ and Base interval $0.15 \mathrm{~mm}$, Fragmentation $5.2 \times 5.2 \mathrm{~mm}$ and separation width $0.65 \mathrm{~mm}$.

The cones were situated in each corner, another two cones were situated in the middle of the part and the last two cones were situated in the middle, between them on both sides The support structure of the Cone was set as follows: Contact to part (r1) $1 \mathrm{~mm}$, Contact to platform (r2) $2 \mathrm{~mm}$. The cones ensure better strength of the support structures and also prevent breaking off of the part from the support structure.

The test samples were oriented in two positions relative to the recoater blade. The first orientation was that the axis of the holes was parallel to the recoater blade. The second orientation was with the axis of the holes perpendicular to the blade.

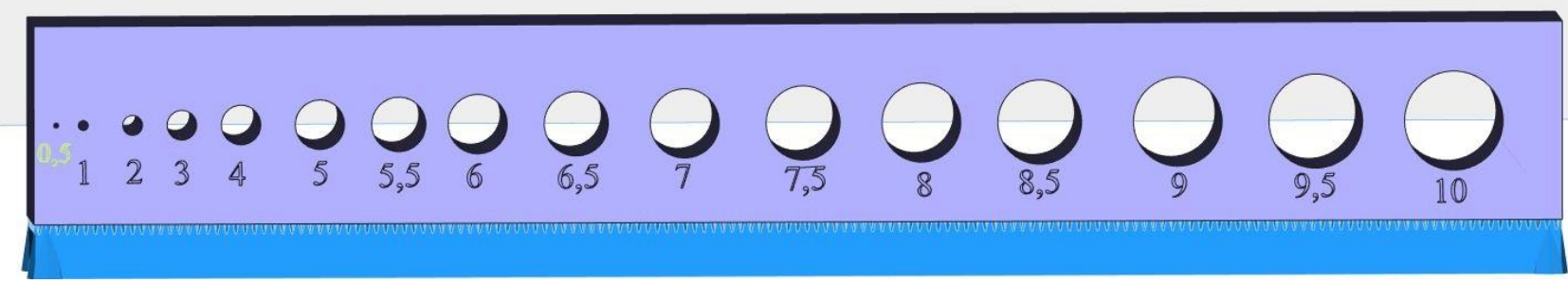

Fig. 2. Test sample

The test samples were printed, and heat treatment was not used after printing. Subsequently, the samples were cut off from the building platform to measure the printed holes on the IFM G4 optical scanning device. Not all the printed holes were scanned, but only representatives were selected and scanned to save time. Selected diameters were: $0.5,1,2,3,5$, 6.5, 7 and $10 \mathrm{~mm}$. These representatives were scanned from both sides. Fig. 3 shows some of the scanned holes.
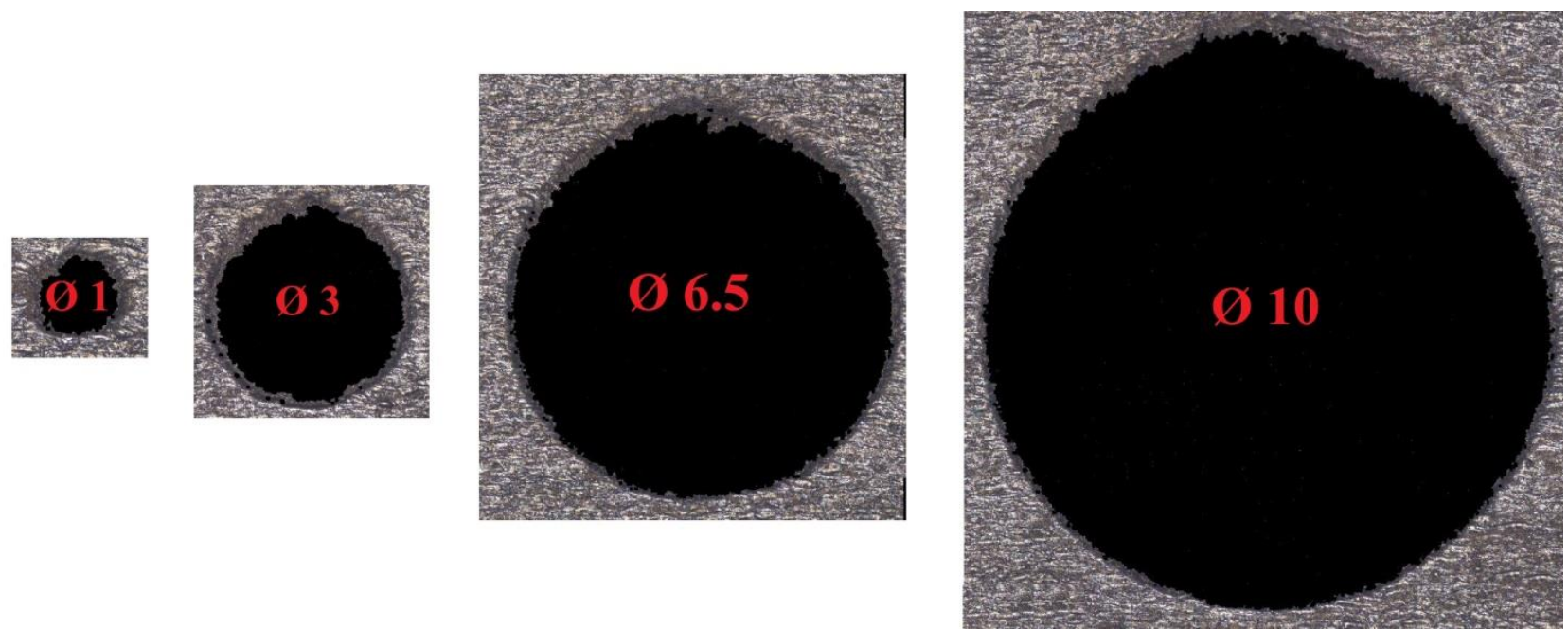

Fig. 3. Printed holes

The scanned holes were measured at $0.2 \mathrm{~mm}$ under the rake plane and the cut views are created in this position. These holes are evaluated using inscribed circles. The shape of the printed holes was not exactly circular, mainly for the small holes. This trend was reflected in holes with diameters $0.5 \mathrm{~mm}, 1 \mathrm{~mm}$ and $2 \mathrm{~mm}$. This can be seen in Fig. 4 . 

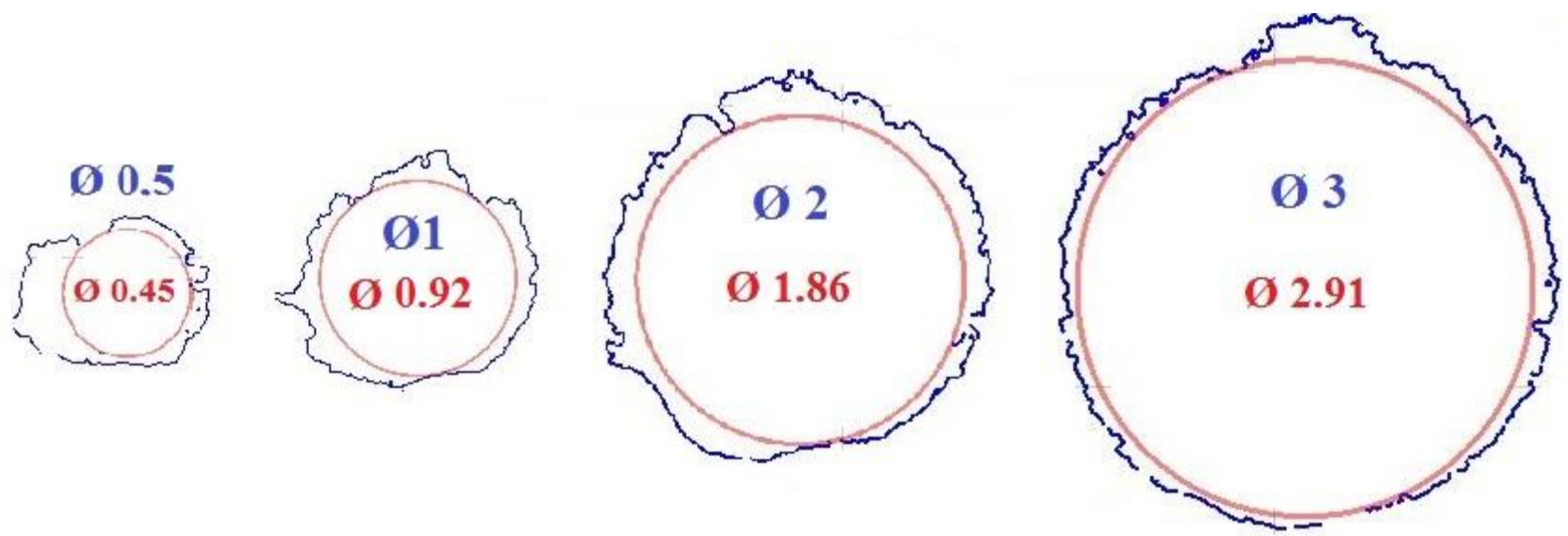

Fig. 4. The holes from 0.5 to $3 \mathrm{~mm}$

Holes larger than $3 \mathrm{~mm}$ showed better circularity, but two areas were identified here where there is a problem with the circular shape. The first area is at the top of the hole. This problem has been described in many studies. A self-supporting angle is more than 45 angles upward from a platform. 'When the building process reaches to the top of the circular cross section the angle of the building direction is below the mentioned critical angle.' [5]

This means that overhangs are created here, resulting in bad geometry and bad surface roughness. Sagging, burning or cavities are created in this area. Taking this into account, the best way to measure these holes is using inscribed circles. The diameter of the inscribed circle has a very good corresponding value. All measured holes have smaller diameters than the model. The measured values of the inscribed holes are listed in Table 2. [5],[9]
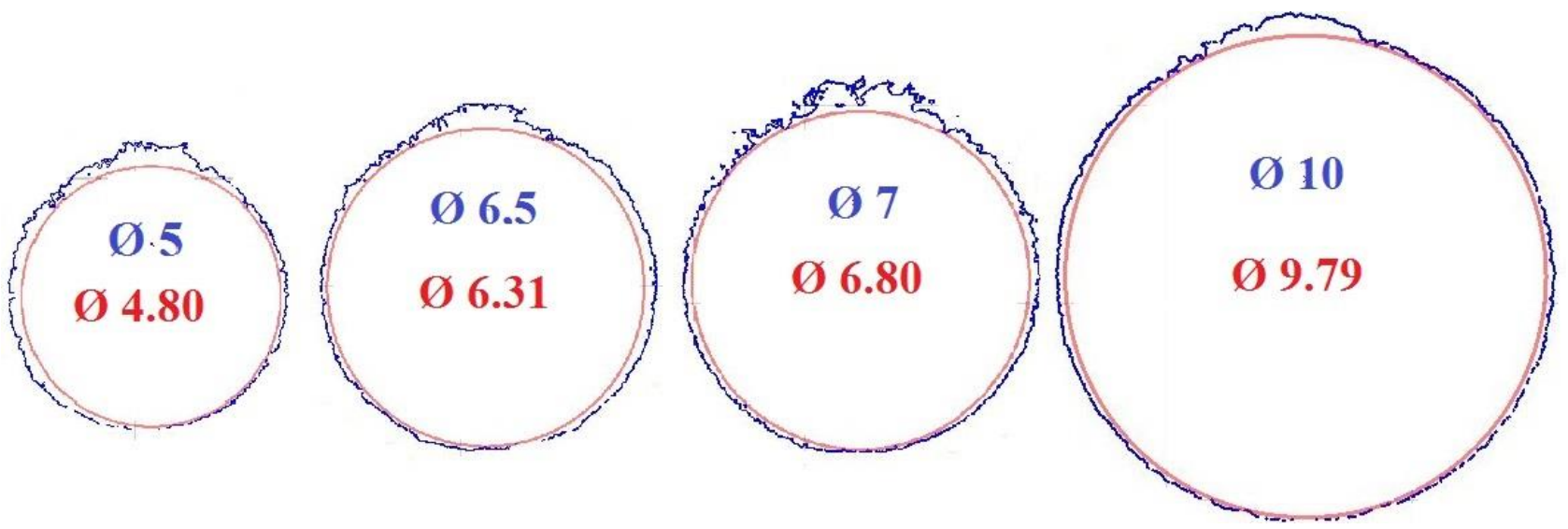

Fig. 5. The holes from 5 to $10 \mathrm{~mm}$

\begin{tabular}{|c|c|c|c|c|}
\hline \multirow{2}{*}{ Diameter } & \multicolumn{2}{|c|}{ Sample oriented in Y } & \multicolumn{2}{c|}{ Sample oriented in X } \\
\cline { 2 - 5 } & Right side & Left side & Right side & Left side \\
\hline 0.5 & 0.458 & 0.37 & 0.398 & 0.358 \\
\hline 1 & 0.932 & 0.862 & 0.926 & 0.81 \\
\hline 2 & 1.858 & 1.848 & 1.858 & 1.802 \\
\hline 3 & 2.862 & 2.81 & 2.916 & 2.826 \\
\hline 5 & 4.778 & 4.694 & 4.802 & 4.842 \\
\hline 6.5 & 6.306 & 6.232 & 6.308 & 6.314 \\
\hline 7 & 6.696 & 6.79 & 6.748 & 6.824 \\
\hline 10 & 9.792 & 9.758 & 9.828 & 9.72 \\
\hline
\end{tabular}

Table 2. Measured values of inscribed circles 
A 'staircase effect' results from the principle of 3D print technology that the parts are built up layer by layer. This defect is most evident when printing cylindrical bodies with a horizontal axis. For this reason, it is not possible to create a part with a smooth continuous surface that has been created by a very complex curve. The 'staircase effect' is shown in Fig. 6.

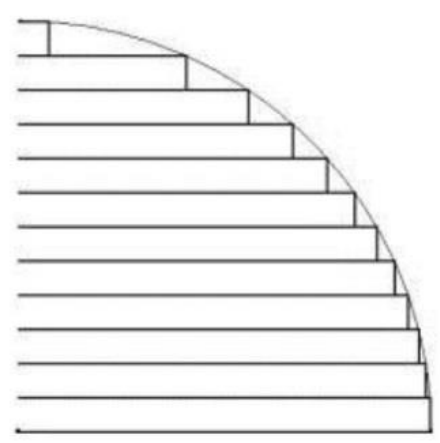

Fig. 6. 'Staircase effect' [13]

This effect causes poor geometry of a hole, even at two locations in one hole. The first location is situated at the beginning of the hole when it is printed. A flat surface (groove) is created in this place and stairs are formed at the ends of this flat surface. The same situation is at the top of the hole, but the experiment is not targeted at this area. It is possible to see the laser paths (hatching) on this flat surface. The width of this flat surface was measured and evaluated using a scanning microscope. The flat surface widths were measured in three locations and the average values are given in Table 3 .
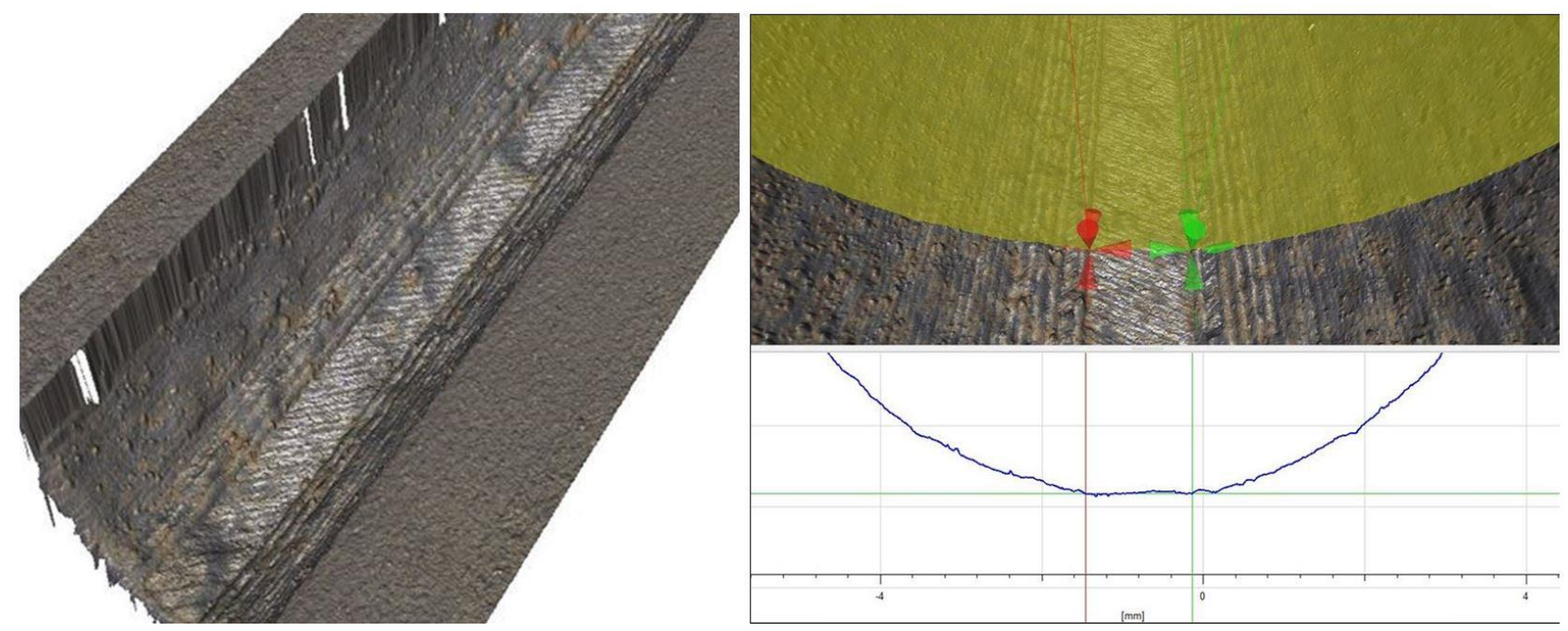

Fig. 7. Flat surface at the bottom of the hole

\begin{tabular}{|c|c|c|}
\hline $\begin{array}{c}\text { Hole } \\
\text { diameter } \\
{[\mathbf{m m}]}\end{array}$ & $\begin{array}{c}\text { Sample } \\
\text { oriented in } \\
{[\boldsymbol{\mu} \mathbf{m}]}\end{array}$ & $\begin{array}{c}\text { Sample } \\
\text { oriented in } \mathbf{X} \\
{[\boldsymbol{\mu m}]}\end{array}$ \\
\hline 1 & 362 & 386 \\
\hline 2 & 345 & 337 \\
\hline 3 & 642 & 641 \\
\hline 5 & 734 & 721 \\
\hline 6.5 & 737 & 728 \\
\hline 7 & 824 & 830 \\
\hline 10 & 1335 & 1330 \\
\hline
\end{tabular}

Table 3. Groove widths at bottom of holes 
The values of the flat surface are dependent on the layer thickness. If the layer thickness is lower, then the width of the flat surface will be thinner. There is no other way to reduce the 'staircase effect'. However, the layer thickness cannot be changed during the printing.

The values in the table correspond approximately to the size of individual layers, but the holes with diameters of 2 mm and $6.5 \mathrm{~mm}$ do not correspond. This is due to the different start positions depending on the printed layer. If the part is sliced into individual layers with a height $0.04 \mathrm{~mm}$, then a situation may occur as in Fig. 8. The start position of the circle may be between slices. This affects the width of the flat surface and explains the different values of the widths of the flat surfaces for holes with diameters of $2 \mathrm{~mm}$ and $6.5 \mathrm{~mm}$.

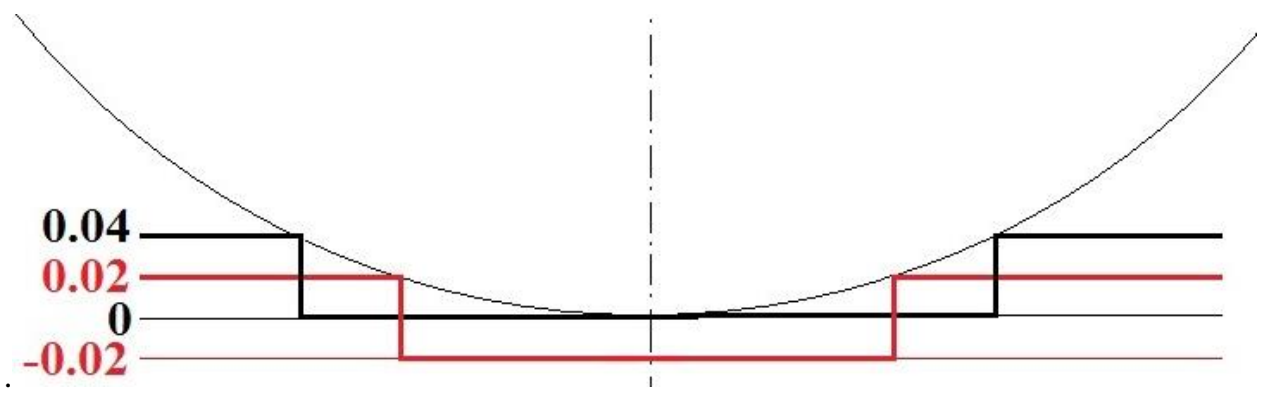

Fig. 8. Offset of start position

\section{Conclusion}

The main goal of the research presented in this paper is to understand the possibilities and limitations of the laser additive manufacturing process in terms of printing internal holes. The experiment confirms that the holes from $0.5 \mathrm{~mm}$ up to a diameter of $10 \mathrm{~mm}$ can be printed without support structures. However, the geometry of the holes is not so perfect; for example, a flat surface is created at the bottom of the holes and in some cases sagging, burning or cavities are created on the upper side. The holes were evaluated using inscribed circles that were measured by an optical-scanning microscope. All printed holes are smaller in diameter than the model. The maximum deviation from the basic size of the hole and the inscribed circle was $-0.306 \mathrm{~mm}$. The deviation was smaller than $0.2 \mathrm{~mm}$ in the majority of cases. The influence of changing the position of the test sample does not show any significant differences.

A flat surface at the bottom of the holes was detected. This problem is generated based on the 'staircase effect'. The 'staircase effect' results from the principle of 3D print technology that the parts are built up layer by layer. The values of the flat surface are dependent on the thickness of the layer and the diameter of the hole. Almost all flat surfaces correspond to the size of the hole and the layer thickness, but the holes with diameters $2 \mathrm{~mm}$ and $6.5 \mathrm{~mm}$ show different values. These differences were caused by the start position of the hole in relation to the printed layer, because the hole may be started between slices. This situation is clearly illustrated in Fig. 8. The geometry of holes is slightly changed during the slicing. It is not possible to create a part with a smooth continuous surface that has been created by a very complex curve.

These holes will be evaluated using differential analysis and further research will be focused on the upper side of the hole. The surface quality and surface roughness will be assessed in this area. It would be appropriate to choose holes with smaller steps between the diameters of the holes for further research.

\section{Acknowledgments}

This contribution has been prepared under the project LO1502 'Development of the Regional Technological Institute' under the auspices of the National Sustainability Programme I of the Ministry of Education of the Czech Republic aimed at supporting research, experimental development and innovation.

\section{References}

[1] Rubesova, K; Jenicek, S; Kana, J\& Zetkova, I; (2016). Microstructure of MS1 Maraging Steel in 3D-Printed Products After Semi-Solid Processing, Proceedings of the 27th DAAAM International Symposium, pp.0467-0472, B. Katalinic (Ed.), Published by DAAAM International, ISBN 978-3-902734-08-2, ISSN 1726-9679, Vienna, Austria

[2] EOS MaragingSteel MS1. EOS. [online]. [cit. 2017-08-10]. Available from: http://ip-saas-eoscms.s3.amazonaws.com/public/1af123af9a636e61/042696652ecc69142c8518dc772dc113/EOS_MaragingSteel_M S1_en.pdf

[3] Kucerova, L. Zetkova, I; (2016). Metallography of 3D Printed 1.2709 Tool Steel. In MANUFACTURING TECHNOLOGY. February 2016, Vol. 16, No.1. s. 140 -144. ISSN 1213-2489 
[4] Dana, M. Zetkova, I. Hanzl, P; (2016). Prining of Thin Walls using DMLS. In MANUFACTURING TECHNOLOGY. October, Vol. 16, No.4. s. 883 -896. ISSN 1213-2489

[5] Additive Metal Manufacturing Inc. [cit. 2017-02-10]. Design for Additive Metal Manufacturing Part I Design for Minimum Impact of DMLS Geometrical Constraints. Canada, [online]. Available from: https://www.additivemet.com/wp-content/uploads/2016/07/design.pdf

[6] Matilainen, V.( 2012.) Benchmarking of laser additive manufacturing process. Bachelor's thesis. Finland Available from: http://www.doria.fi/bitstream/handle/10024/84863/BSc\%20Thesis\%20Matilainen\%20fv.pdf? sequence=1

[7] EPMA European Powder Metallurgy Association. Introduction to additive manufacturing technology - A guide for Designers and Engineers. Available from: http://www.epma.com/doc_details/427-introduction-to-additivemanufacturing-technology

[8] Hanzl, P; Zetek, M\& Zetkova, I (2016). Cellular Lattice Structure Produced by Selective Laser Melting and its Mechanical Properties, Proceedings of the 26th DAAAM International Symposium, pp.0748-0752, B. Katalinic (Ed.), Published by DAAAM International, ISBN 978-3-902734- 07-5, ISSN 1726-9679, Vienna, Austria

[9] Hanzl, P., Zetek, M., Baksa, T., Kroupa, T. (2015). The influence of processing parameters on the mechanical properties of SLM parts. In Procedia Engineering. Vienna: Elsevier, s. 1405-1413. ISBN: 978-3-901509-99-5 ISSN: 1877-7058

[10] N. C. Balc, P. Berce, R. Pacurar, (2010) Comparison between SLM and SLS in producing complex metal parts, Annals of DAAAM for 2010 \& Proceeding of the 21st International DAAAM Symposium, Volume 21, No. 1, ISSN 1726-9679, Vienna, Austria.

[11] Hronek, O., Zetek, M., Baksa, T., Adamek, P. (2016). Influences Of Holders Speed On The Cutting Edge During Drag Finishing. Manufacturing Technology, Vol. 16, No. 5, s. 933-939. ISSN: 1213-2489

[12] Thomas Daniel. The Development of Design Rules for Selective Laser Melting. Ph.D. Thesis National Centre for Product Design \& Development Research University of Wales Institute. Available from: https://repository.cardiffmet.ac.uk/dspace/handle/10369/913

[13] Zetkova, I., Zetek, M., Dana, M., Kutlwaser, J. (2016). Critical Parameters of Metal Laser Sintering with its Impact on Geometrical Accuracy of a Component. Manufacturing Technology, Vol. 16, No. 5, s. 1216-1222. ISSN: 12132489 